\section{Reply to eLetter by Feldtkeller et al}

Thank you to Drs Feldtkeller and Rudwaleit ${ }^{1}$ for your interest in and comments on our paper. ${ }^{2}$

In the study, which was based on a large number of patients, we investigated the time between symptom onset and diagnosis during the last 10 years. Our analysis was presented at the European League Against Rheumatism 2013 before a large audience and subsequently the paper was scrutinised by three independent reviewers, who had no comments on the choice of method. In the paper, and in the subsequent letter, we discussed and acknowledged a number of potential methodological challenges in an observational setting like this, including the risk of right censorship. ${ }^{2} 3$ Based on your comments, however, we acknowledge that this bias arising from patients who have symptoms, but not yet have been diagnosed and, therefore, not included in the data set, may have a larger impact than we understood at the time when the paper was written.

\section{Jan Sørensen, ${ }^{1}$ Merete Lund Hetland ${ }^{2,3}$}

${ }^{1}$ Centre for Applied Health Services Research, University of Southern Denmark, Odense, Denmark

${ }^{2}$ DANBIO registry, Copenhagen Center for Arthritis Research, Center for Rheumatology and Spine Diseases, Glostrup Hospital, Glostrup, Denmark ${ }^{3}$ Department of Clinical Medicine, Faculty of Health and Medical Sciences, University of Copenhagen, Copenhagen, Denmark

Correspondence to Dr Merete Lund Hetland, Center for Rheumatology and Spine Diseases, Glostrup Hospital, Nordre Ringvej 57, DK-2600 Glostrup, Denmark; Merete.hetland@dadlnet.dk
Competing interests None.

Provenance and peer review Commissioned; internally peer reviewed.

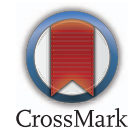

To cite Sørensen J, Hetland ML. Ann Rheum Dis 2014;73:e78.

Received 18 September 2014

Accepted 19 September 2014

Published Online First 3 October 2014

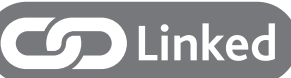

http://dx.doi.org/10.1136/annrheumdis-2014-206126

Ann Rheum Dis 2014;73:e78. doi:10.1136/annrheumdis-2014-206612

\section{REFERENCES}

1 Feldtkeller E, Rudwaleit M. Comment on 'Diagnostic delay in patients with rheumatoid arthritis, psoriatic arthritis and ankylosing spondylitis: results from the Danish nationwide DANBIO registry'. Ann Rheum Dis 2014; 73:e77.

2 Sørensen J, Hetland ML. Diagnostic delay in patients with rheumatoid arthritis, psoriatic arthritis and ankylosing spondylitis: results from the Danish nationwide DANBIO registry. Ann Rheum Dis 2014. Published Online First: 17 Feb 2014. doi:10.1136/annrheumdis-2013-204867

3 Sørensen J, Hetland ML. Decreases in diagnostic delay are supported by sensitivity analyses. Ann Rheum Dis 2014;73:e45. 